\title{
Data divorce
}

\section{The US Department of Health and Social Security's Public Health Service (PHS) ruled in 2005 that "Plagiarism is the appropriation of another person's ideas, processes, results, or words without giving appropriate credit." Despite this, its Office of Research Integrity (ORI) risks giving the wrong impression that plagiarists have enduring conjugal rights to former collaborators' ideas.}

W e found this discrepancy prominently posted on the ORI website. The official definition can be found in a document entitled 42 CFR Parts 50 and 93 Public Health Service Policies on Research Misconduct; Final Rule (Fed. Regist. 70(94), 28370-28400, 2005).

On p. 28377:

III. Significant Comments Not Resulting in Changes

A. Definition of Research Misconduct, Sec. 93.103.. Although most commentators supported the new definition of research misconduct, there were a number of comments recommending changes, including that:... (3) the definition of plagiarism should expressly exclude authorship and credit disputes;

And then on p. 28386:

$\$ 93.103$ Research misconduct...

(c) Plagiarism is the appropriation of another person's ideas, processes, results, or words without giving appropriate credit.

It is clear from this final rule that, although it was challenged to do so, the PHS did not change its definition of plagiarism to exclude authorship and credit disputes. Unfortunately, the ORI uses a different definition (http://ori.dhhs.gov/policies/ plagiarism.shtml):

\begin{abstract}
Many allegations of plagiarism involve disputes among former collaborators who participated jointly in the development or conduct of a research project, but who subsequently went their separate ways and made independent use of the jointly developed concepts, methods, descriptive language, or other product of the joint effort. The ownership of the intellectual property in many such situations is seldom clear, and the collaborative history among the scientists often supports a presumption of implied consent to use the products of the collaboration by any of the former collaborators.
\end{abstract}

For this reason, ORI considers many such disputes to be authorship or credit disputes rather than plagiarism. Such disputes are referred to PHS agencies and extramural institutions for resolution.

There must be many more cases of plagiarism than the ORI investigates each year, according to one of its own surveys (S.L. Titus et al., Nature 453, 980-982, 2008). Of course, we would prefer that all such cases be uncovered and corrected, though this may be too much to ask of one national agency. But by providing a channel for fair and accountable investigation, the ORI also provides an important deterrent to scientific misconduct, not only for US researchers but, by example, for the global research community. Therefore, we suggest that it is counterproductive to the reporting of misconduct-and to the deterrence of misconduct-for the ORI to be seen to be turning away a significant proportion of its cases. Indeed, these are the very cases in which thefts of data and ideas are most likely to occur.

We recognize that science depends upon trust, credit and attribution (http://www.nature.com/authors/editorial_policies/ publication.html).

We accept that prevention is the most important aspect of research integrity and that responsibility for that lies with the institutions that lay claim to researchers' data, lab notebooks and intellectual property (Editorial, Nature 453, 957, 2008). Some solutions that institutions can provide are technical, for example, dedicated servers and electronic lab notebooks to encourage systematic recording of data, first discoveries and ideas. Some are cultural, entailing institutional endorsement of simple rules for collaboration that make collaborators take responsibility for the security of their own data and ideas (such as the useful checklist provided by the US National Institutes of Health Ombudsman at http://www.nih.gov/catalyst/2002/02.05.01/page6.html). Far from detracting from the spontaneity of new collaboration, an explicit written record of roles and expectations is often a key to its success (H. Ledford, Nature 452, 682-684, 2008).

We ask the ORI to please correct its definition of plagiarism to the one published by its parent body and to distinguish that definition from its own practice of deferring for investigation at the institutional level accusations of plagiarism leveled at collaborators and coauthors. 